\title{
Natalizumab Risk Stratification: Role of a Two- Step Anti-JCV Antibody Assay
}

\author{
Paul W. O'Connor
}

Can J Neurol Sci. 2012; 39: 670-675

Natalizumab is a monoclonal antibody that is administered as a once monthly infusion for the treatment of patients with relapsing multiple sclerosis (MS). ${ }^{1}$ Its efficacy was demonstrated in the AFFIRM phase III clinical trial, which reported statistically significant reductions in annualized relapse rate (68\%), sustained disability progression (42-54\% over two years), and gadolinium-enhancing (92\%) and T2 (83\%) lesion burden on magnetic resonance imaging (MRI) (all $\mathrm{p}<0.001$ compared to placebo). ${ }^{2}$ The therapeutic benefits of natalizumab were further supported by a retrospective analysis of the AFFIRM study, which reported a 5.3-fold greater proportion of patients who were free of clinical and radiological disease activity (37\% vs. $7 \%$ for placebo). ${ }^{3}$ Notably, the effects of natalizumab were consistent across subgroups of patients with or without highly active disease at baseline. Studies have also shown that natalizumab has beneficial effects on visual acuity ${ }^{4}$ and on quality of life. ${ }^{5}$ However, this high level of efficacy must be balanced against the risk of rare, albeit very serious, adverse events, including progressive multifocal leukoencephalopathy (PML), hepatic injury, and hypersensitivity reactions. ${ }^{1}$

Progressive multifocal leukoencephalopathy is a rare, opportunistic condition caused by a common polyomavirus called JC virus (JCV) ${ }^{6,7}$ While the vast majority of people who have been exposed to JCV remain asymptomatic, in rare cases, the virus undergoes mutation that enables lytic infection of myelin-producing oligodendrocytes and subsequent development of PML. ${ }^{8}$ The condition has typically been reported in immune-compromised patients, including those with HIV, or patients who have undergone cancer chemotherapy or organ transplantation. ${ }^{7,9}$ More recently, cases of PML have been reported in non-MS patients receiving biologic therapies including efalizumab, alemtuzumab, rituximab, and natalizumab. ${ }^{10}$ Two cases of PML were reported in the phase III study of natalizumab in combination with interferon $\beta-1 \mathrm{a}^{11,12}$ and a third case was discovered posthumously in a patient in the phase III study of natalizumab for the treatment of Crohn's disease. ${ }^{13}$ Since then there have been 212 cases of PML in natalizumab-treated MS patients in the post-marketing setting (as of February 29, 2012), representing an estimated incidence of 2.13/1,000 patients. ${ }^{14}$ Notably, post-trial cases of natalizumabassociated PML have occurred in patients receiving this agent in isolation, therefore it is unlikely that the combination with interferon $\beta$-1a contributed substantially to PML risk. The mortality rate of natalizumab-associated PML is approximately $22 \%,{ }^{14,15}$ considerably lower than the mortality rate that has been reported for PML in general $(\sim 50 \%))^{7,16}$ This lower rate of mortality in MS patients may be accounted for, at least in part, by the use of plasma exchange (PLEX) in most patients who developed PML, resulting in the accelerated removal of natalizumab from the circulation and a hastened restoration of immune function. ${ }^{17}$ Levels of disability among survivors are variable and approximately evenly distributed between mild, moderate and severe, based on physician-rated Karnofsky scores. ${ }^{15}$ Earlier diagnosis through enhanced clinical vigilance and management may further improve outcomes of patients developing PML. ${ }^{18}$

Evidence to date suggests that PML is caused by a convergence of multiple risk factors. Notably, infection by JCV is a pre-requisite for the development of PML. ${ }^{19}$ In patients treated with natalizumab, two other risk factors must be considered, namely exposure to prior immunosuppressant therapy (e.g., mitoxantrone, azathioprine, methotrexate, cyclophosphamide, mycophenolate, etc.) and duration of natalizumab treatment. ${ }^{20}$ While there is no apparent pattern in type or duration of prior immunosuppressant use, the increase in risk is most pronounced after two years of natalizumab therapy (Figure 1). ${ }^{14}$ Data beyond four years are limited.

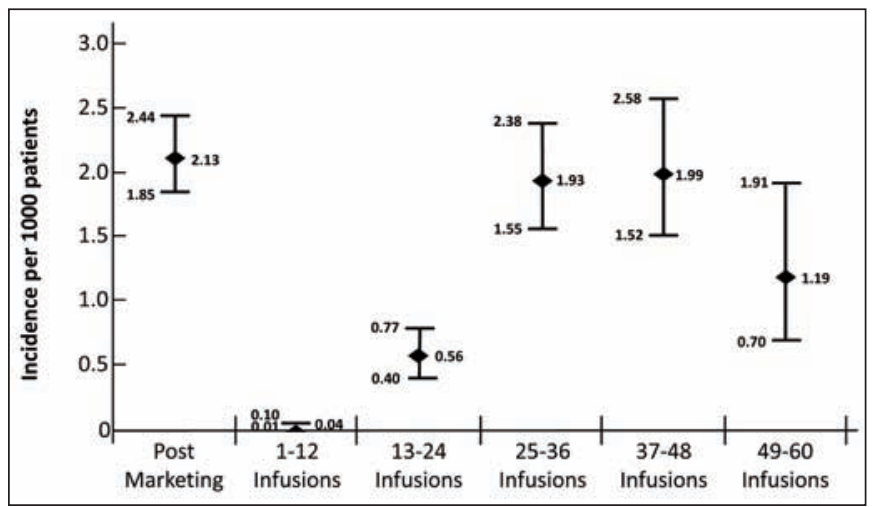

Figure 1: Natalizumab-associated PML incidence estimates by treatment epoch. Incidence estimates by treatment epoch were calculated based on natalizumab exposure through February 29, 2012 and 212 confirmed cases as of February 29, 2012. The incidence for each epoch was calculated as the number of PML cases divided by the number of patients exposed to natalizumab (e.g., for 25 to 36 infusions all PML cases diagnosed during this period was divided by the total number of patients ever exposed to at least 25 infusions and therefore having risk of developing PML during this time). The 95\% confidence interval (CI) is an estimated range that is $95 \%$ likely to include the true rate of PML.

From the Department of Neurology, St. Michael's Hospital, Toronto, Ontario, Canada.

Received February 21, 2012. Final Revisions Submitted May 4, 2012. Correspondence to: Paul W. O'Connor, Department of Neurology, St. Michael's Hospital, 30 Bond Street, Toronto, Ontario, M5B 1W8, Canada.

Email: oconnorp@smh.toronto.on.ca. 


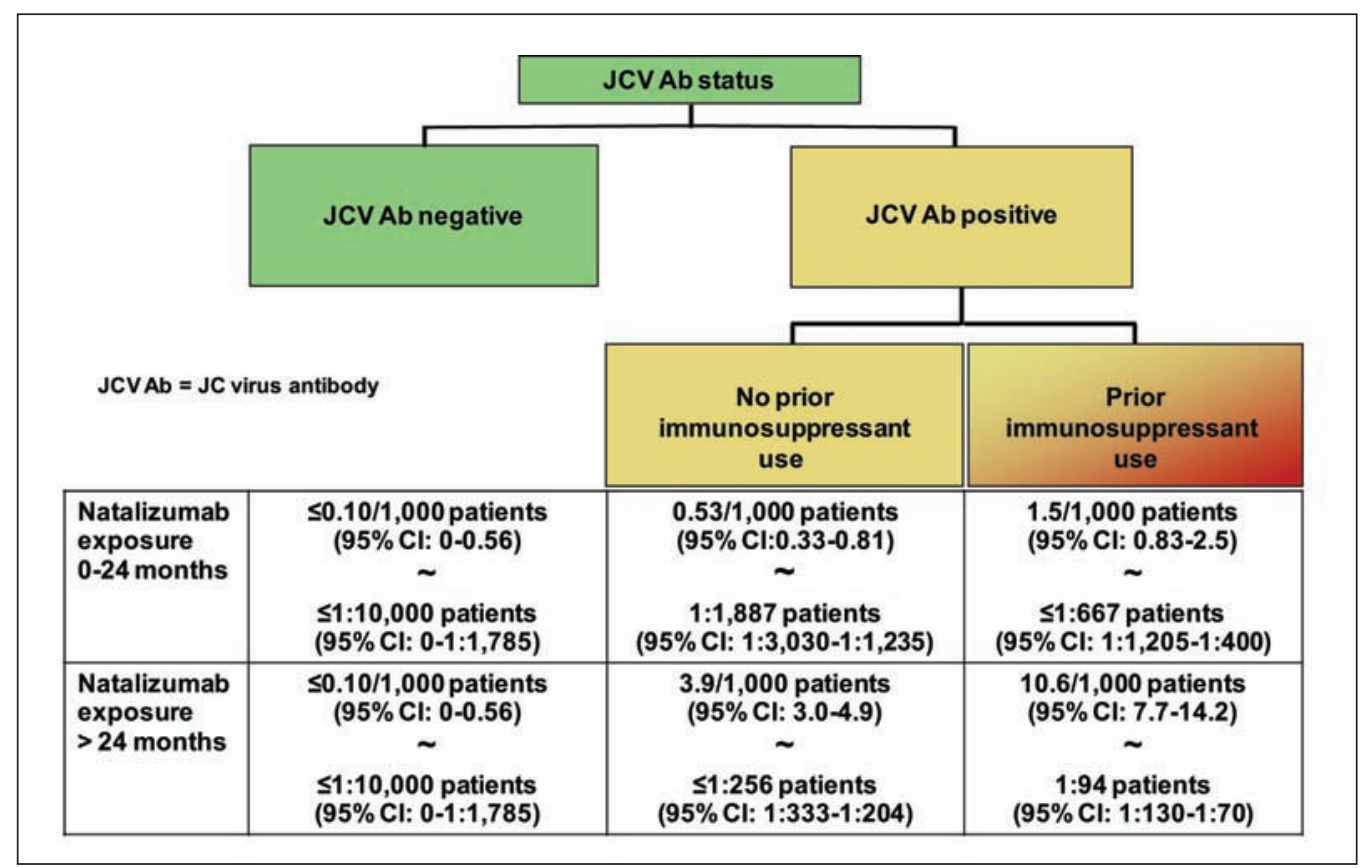

Figure 2: Estimated incidence of PML stratified by serum anti-JCV antibody status, prior immunosuppressant use and natalizumab treatment duration. Reproduced with permission from Sørensen et al. ${ }^{20}$ The lowest risk group consists of those that are anti-JCV antibody negative. The estimate is based on the assumption that all antibodynegative patients receiving at least one dose of natalizumab and one hypothetical PML case that was anti-JCV antibody negative at the time of PML diagnosis. The highest risk group consists of those who test positive for antiJCV antibodies, had prior immunosuppressant use, and received more than 2 years of natalizumab treatment. This algorithm assumed: that all 159 confirmed cases of PML as of September 1 st 2011 were anti-JCV antibody positive prior to PML diagnosis; that $55 \%$ of the patients were anti-JCV antibody positive; and that $20 \%$ had prior use of immunosuppressants.

Polymerase chain reaction (PCR) tests to detect JCV DNA in the blood or urine are commercially available. However their sensitivity was found to be inadequate to monitor the risk of PML based on an evaluation of samples from almost 1,400 patients involved in the major natalizumab clinical trials. ${ }^{21}$ Recently, a two-step enzyme-linked immunosorbent assay (ELISA) test to detect anti-JCV antibodies in serum and plasma (as evidence of host immune response to JCV infection) was developed and is being evaluated in clinical trials. ${ }^{19}$ This test offers increased sensitivity and specificity over existing antiJCV antibody tests because of its confirmatory second step, which distinguishes patients with anti-JCV-specific antibodies from those with potentially low-affinity or cross-reactive antibodies. The assay cut-off points were established using samples from 831 natalizumab-treated subjects from the STRATA study. ${ }^{19}$ The assay has a false negative rate of 2.5 to $2.7 \%{ }^{19,22}$ Serum samples from several MS patient groups have been evaluated with this assay, with a mean anti-JCV seroprevalence rate of 54\% $19,20,22,23$ and an annual conversion rate of approximately $2 \% .{ }^{19}$ Seroprevalence rates tend to increase after 50 years of age, are higher in males and vary with geography, with higher rates in patients in Europe and North America, and lower rates in the United Kingdom and Australia/New Zealand. ${ }^{19}$ Data from larger, multinational cohorts indicate these geographical differences are minimal and seroprevalence remains in the approximate range of $50-60 \% .22$
A PML risk stratification algorithm has been recently proposed based on prior immunosuppressant use, natalizumab treatment duration, and anti-JCV antibody status. ${ }^{24}$ The algorithm was recently published in a review by Sørensen et al (Figure 2). ${ }^{20}$ The estimated incidence was based on 159 confirmed cases of PML (as of September 1, 2011), who were all assumed to be anti-JCV antibody positive prior to PML diagnosis. The algorithm also assumes that $55 \%$ of the patients were anti-JCV antibody positive and that $20 \%$ had prior use of immunosuppressants. The estimated incidence of PML in antibody-negative patients was conservatively estimated assuming one hypothetical case of PML in an anti-JCV antibodynegative patient.

It is anticipated that the two-step anti-JCV antibody assay will soon be commercially available in Canada and that it will help further refine PML risk stratification to allow more appropriate use of various therapies such as natalizumab. The following recommendations relating to the role of the two-step anti-JCV antibody assay in risk stratification of MS patients currently on or considering treatment with natalizumab, were developed by an expert panel of Canadian neurologists specialized in the management of patients with MS and experienced with natalizumab therapy that convened in May, 2011. This paper builds on a previously published commentary on the use of natalizumab in MS patients, ${ }^{25}$ to help further guide Canadian clinicians on how to optimize the use of natalizumab in clinical 
practice. One of the objectives of this meeting was to develop a clear and practical set of consensus-based, non-binding recommendations on the use of the anti-JCV antibody assay to risk stratify patients and to make decisions relating to natalizumab treatment based on available evidence and the panel's experience with the assay to date.

These recommendations discuss issues related to patient selection, initiation and maintenance of treatment, and monitoring of patients receiving natalizumab based on five distinct clinical scenarios according to the three quantitatively defined risk factors for the development of natalizumab-related PML: anti-JCV antibody serostatus, prior immunosuppressant exposure, and duration of natalizumab treatment. The recommendations for risk stratification by this expert panel are summarized in the Table.

\section{Risk Stratification For Patients Who Are Anti-Jcv Antibody Negative}

Patients who are anti-JCV antibody-negative are at the lowest risk of developing PML. Indeed, all patients who have developed PML to date and who had samples available for analysis were found to be anti-JCV antibody-positive. ${ }^{19}$ Seronegative status could therefore increase comfort with natalizumab as a treatment option from both the patient's and the clinician's perspective, so long as the patient remains seronegative (the estimated annual conversion rate is $2 \%) .{ }^{19}$ Clinicians should bear in mind that the assay has an estimated false negative rate of 2.5 to $2.7 \% .^{19,22}$

Assurance of seronegativity may increase the pool of patients who could be considered candidates for natalizumab treatment. Notably, natalizumab could be considered a first-line treatment option in patients who are anti-JCV antibody-negative, even in those with milder MS disease severity. Currently, the

Table: Summary recommendations for risk stratification of patients by anti-JCV antibody serostatus, prior immunosuppressant use, and duration of natalizumab exposure

\begin{tabular}{|c|c|c|c|c|c|}
\hline $\begin{array}{l}\text { Anti-JCV antibody } \\
\text { serostatus }\end{array}$ & Negative & Positive & Positive & Positive & Positive \\
\hline $\begin{array}{l}\text { Prior immunosuppressant } \\
\text { use }\end{array}$ & Yes or no & No & No & Yes & Yes \\
\hline $\begin{array}{l}\text { Duration of natalizumab } \\
\text { treatment }\end{array}$ & $0-2$ years & $0-2$ years & $>2$ years & $0-2$ years & $>2$ years \\
\hline $\begin{array}{l}\text { Estimated risk of PML } \\
(95 \% \mathrm{CI})\end{array}$ & $\begin{array}{l}\leq 0.10 / 1000 \\
(0-0.56)\end{array}$ & $\begin{array}{l}0.53 / 1000 \\
(0.33-0.81)\end{array}$ & $\begin{array}{l}3.9 / 1000 \\
(3.0-4.9)\end{array}$ & $\begin{array}{l}1.5 / 1000 \\
(0.83-2.5)\end{array}$ & $\begin{array}{l}10.6 / 1000 \\
(7.7-14.2)\end{array}$ \\
\hline Initiation of natalizumab & $\begin{array}{l}\text { Consider } \\
\text { natalizumab as a } \\
1^{\text {st }} \text {-line therapy in } \\
\text { many cases, } \\
\text { including patients } \\
\text { with milder } \\
\text { disease. } \\
\text { An appropriate } \\
\text { choice when } \\
\text { switching from } \\
\text { conventional } \\
\text { DMT. }\end{array}$ & $\begin{array}{l}\text { Assay result does not } \\
\text { change strategy } \\
\text { during first } 2 \text { years } \\
\text { because PML risk is } \\
\text { low. } \\
\text { Inform patient of } \\
\text { seropositivity. }\end{array}$ & N/A & $\begin{array}{l}\text { Discuss risk of } \\
\text { PML with } \\
\text { patient. } \\
\text { These patients } \\
\text { often have } \\
\text { aggressive } \\
\text { disease. } \\
\text { Need for } \\
\text { effective } \\
\text { treatment may } \\
\text { outweigh risk. }\end{array}$ & $\mathrm{N} / \mathrm{A}$ \\
\hline $\begin{array}{l}\text { Maintenance of } \\
\text { natalizumab treatment }\end{array}$ & $\begin{array}{l}\text { Continue as long } \\
\text { as effective and } \\
\text { seronegative } \\
\text { (spares drug } \\
\text { holidays). } \\
\text { Risk } \\
\text { remains } \leq 0.10 / 100 \\
0 \text { with every } \\
\text { negative test. }\end{array}$ & $\begin{array}{l}\text { Maintain (if effective) } \\
\text { until } 2 \text { years then } \\
\text { reassess benefits and } \\
\text { risks. }\end{array}$ & $\begin{array}{l}\text { Discuss risk with } \\
\text { patient. } \\
\text { Probably continue } \\
\text { natalizumab if } \\
\text { aggressive disease; } \\
\text { less compelling in } \\
\text { mild-to-moderate } \\
\text { disease }\end{array}$ & $\begin{array}{l}\text { Maintain (if } \\
\text { effective) until } 2 \\
\text { years then } \\
\text { reassess benefits } \\
\text { and risks. }\end{array}$ & $\begin{array}{l}\text { Discuss risk of } \\
\text { continued therapy } \\
\text { and other } \\
\text { potential } \\
\text { treatment options. }\end{array}$ \\
\hline $\begin{array}{l}\text { Monitoring and } \\
\text { management }\end{array}$ & $\begin{array}{l}\text { Routine } \\
\text { examination (at } \\
\text { least every } 6 \\
\text { months) } \\
\text { Annual MRI }\end{array}$ & $\begin{array}{l}\text { Routine examination } \\
\text { (at least every } 6 \\
\text { months) } \\
\text { Annual MRI }\end{array}$ & $\begin{array}{l}\text { Increased clinical } \\
\text { vigilance: } \\
\text { examination at least } \\
\text { every } 6 \text { months. } \\
\text { MRI every } 6-12 \\
\text { months }\end{array}$ & $\begin{array}{l}\text { Routine } \\
\text { examination (at } \\
\text { least every } 6 \\
\text { months) . } \\
\text { MRI every 6-12 } \\
\text { months }\end{array}$ & $\begin{array}{l}\text { Heightened } \\
\text { clinical vigilance: } \\
\text { examination at } \\
\text { least every } 6 \\
\text { months. } \\
\text { MRI every 6-12 } \\
\text { months }\end{array}$ \\
\hline $\begin{array}{l}\text { Re-test for anti-JCV } \\
\text { antibodies? }\end{array}$ & $\begin{array}{l}\text { Yes - annually as } \\
\text { long as patient } \\
\text { remains } \\
\text { seronegative }\end{array}$ & No & No & No & No \\
\hline
\end{tabular}


natalizumab label in Canada allows for first-line treatment only in patients who have rapidly-evolving severe MS (REMS), defined as two or more disabling relapses with incomplete recovery within one year, or two or more moderate to severe relapses with complete recovery within one year and MRI evidence of active disease. ${ }^{25}$ More typically, MS patients in Canada receive natalizumab as an escalation therapy after failure of treatment with a traditional disease-modifying drug (DMD). Patients with established anti-JCV seronegativity who experience ongoing or breakthrough disease activity despite treatment with DMDs have a very low risk of PML. As such, the decision to switch such patients to natalizumab may occur earlier in their treatment course.

Since the development of PML is contingent on JCV infection, the other two quantified risk factors for PML in natalizumab-treated patients, namely prior immunosuppressant use and duration of natalizumab therapy, do not influence the risk of PML as long as a patient remains anti-JCV antibodynegative. Given that the annual rate of seroconversion is in the order of $2 \%,{ }^{19}$ seronegative patients should be re-tested annually. In patients who seroconvert, the other two risk factors then become important considerations in treatment decision-making (see subsequent sections on recommendations for seropositive patients). For example, patients who have been receiving natalizumab for $>2$ years would be placed in a higher-risk category than those who seroconvert within the first two years of natalizumab treatment. Likewise, patients with a prior history of immunosuppressant use would be considered at higher risk of PML than those who had never used these agents. Thus, sequencing of MS therapies should be carefully considered in light of the availability of the anti-JCV antibody assay. Based on the limited long-term safety data currently available for fingolimod, a conservative approach at this time would be to consider it as an immunosuppressive agent. Other therapeutic options should be discussed with the patient if seroconversion occurs to establish their risk tolerance for continued treatment with natalizumab and to explore the risks and benefits of treatment alternatives.

Patients who remain anti-JCV antibody-negative could potentially be continued on natalizumab indefinitely, based on the individual judgment of the clinician. The estimated risk of PML can be considered to be $\leq 0.10 / 1,000^{20}$ as long as the antiJCV antibody test result remains negative. Knowledge of continued seronegativity can therefore eliminate the practice of natalizumab "drug holidays." This is important since natalizumab efficacy requires continued treatment, and disease activity has been shown to return to pre-treatment levels within four months of discontinuation. ${ }^{26}$

Recommendations for the management and follow-up of antiJCV antibody-negative patients are similar to those for MS patients in general, with the addition of annual anti-JCV antibody testing to assess for seroconversion. Specifically, patient visits should be scheduled at least every six months or as clinically indicated. Magnetic resonance imaging scans should be obtained according to individual hospital protocols, usually annually. Clinicians should continue to be vigilant for signs and symptoms of PML in all patients receiving natalizumab; readers are encouraged to refer to the previously published recommendations $^{25}$ for more complete information on monitoring for signs suggestive of PML.

\section{Risk Stratification for Patients Who Are Anti-JCV Antibody Positive \\ With No Prior Immunosuppressant Treatment and 0-2 Years of Natalizumab Exposure}

Patients in this category are at low risk of PML during the first two years of treatment with natalizumab. In general, the panel felt that a positive result for the anti-JCV antibody assay in patients without prior immunosuppressant use will not greatly change management strategies compared to current practice (i.e., prior to the assay availability). Patients should be informed of their anti-JCV antibody status; seropositivity should not necessarily negate the use of natalizumab in appropriate patients who would be expected to benefit from treatment. Specifically, natalizumab can continue to be considered a first-line therapy in patients with aggressive disease to rapidly attenuate the disease activity, even in patients who are anti-JCV antibody-positive. Although natalizumab may also be considered as a treatment option in patients with mild-to-moderate MS, this expert panel believes the indication for first-line treatment is less compelling in patients who are anti-JCV antibody-positive than it is in antiJCV antibody-negative patients.

The anti-JCV antibody assay can be helpful in assisting with risk/benefit discussions with patients, since it further quantifies the risk of PML. Based on the natalizumab clinical trial population and early post-marketing population, the estimated risk of PML was approximately $1 / 1,000 .{ }^{26}$ Confirmation of antiJCV seropositivity reduces the estimated risk to $1 / 1,887$ during the first two years of treatment in patients with no prior immunosuppressant use.$^{20}$ Clinicians are encouraged to continue to re-assess benefits and risks in patients after two years of natalizumab treatment, and patients should be informed that their risk category changes after two years. Decisions to continue natalizumab treatment beyond two years will depend both on the degree of treatment efficacy and on patient preference. If there is active disease despite natalizumab treatment, there may be no compelling reason to maintain treatment, whereas if treatment is effective, the patient may choose to continue if their perceived benefits outweigh the risk of PML with longer-term treatment.

Patients who are seropositive for anti-JCV antibodies do not need to be re-tested. As a conservative approach, this expert panel considers patients "once positive, always positive" with respect to anti-JCV serostatus. Patients in this category should be monitored according to routine practice, with clinical evaluation at least every 6 months and annual MRI. Clinical vigilance for the signs and symptoms of PML is strongly encouraged, since JCV infection is a prerequisite for the development of PML.

\section{With No Prior Immunosuppressant Treatment and >2 Years of Natalizumab Exposure}

The estimated incidence of PML increases from one in 1,887 patients in the two years of treatment, to approximately one in 256 patients beyond two years, in patients who have not been previously exposed to immunosuppressant therapy. ${ }^{20}$ Patients who have been receiving natalizumab for longer than two years who are tested for the first time and who are found to be seropositive, should re-assess their risk/benefit profile. In patients with aggressive MS who are responding well, continuation of natalizumab therapy should be considered to 
maintain disease control. The decision to continue treatment beyond two years in patients with mild or moderate MS was felt by the panel to be less compelling. However, clinicians are encouraged to discuss risks and benefits with individual patients to determine their risk tolerance and to explore other treatment options that might be available should the benefits not be felt to outweigh the potential risks of continued therapy.

Increased clinical vigilance is warranted in this patient segment, with clinical examination at least every six months. Clinicians may consider more frequent MRI (e.g., every 6-12 months, depending on hospital protocols) to assess for disease breakthrough and/or signs suggestive of PML, since there have been reports of increased gadolinium enhancement in patients at the time of PML suspicion. ${ }^{7,16}$ Clinicians may choose to test a patient's cerebrospinal fluid for the presence of JCV if new lesions develop. Early identification and treatment of PML has been associated with improved survival and outcomes in natalizumab-treated patients. ${ }^{15}$

\section{With Prior Immunosuppressant Treatment and 0-2 Years of Natalizumab Exposure}

Risk of PML is low for the first two years of treatment with natalizumab, although it is higher in patients who have previously been exposed to immunosuppressants than in those who have not (i.e., $1.5 / 1,000$ vs. $0.53 / 1,000) .^{20}$ Treatment may only be desired for a limited amount of time based on an individual patient's tolerance of risk. Therefore, clinicians should engage patients in this risk category in a risk/benefit discussion when the patient's serostatus becomes known, and benefits and risks should be revisited once exposure to natalizumab has reached two years.

Patients who have a history of immunosuppressant use most likely have aggressive disease that was not adequately controlled on conventional DMDs and/or immunosuppressive therapy. Some of these patients may also have progressive disease that may continue to progress despite continued natalizumab treatment. The need for an effective treatment in this patient segment - and the limited treatment options that remain available to them - may therefore outweigh the risk of PML. Clinicians are reminded that data beyond four years are limited; it is not known at this time how risk evolves beyond four years of natalizumab treatment.

Although there is no evidence of an association between the type or duration of immunosuppressant use and PML risk, the majority of patients who developed PML in the post-marketing setting who had previously been exposed to immunosuppressants had in fact received mitoxantrone. Among 47 of 125 patients who developed PML, the types of prior immunosuppressant(s) included the following (some patients received multiple immunosuppressant therapies; does not include use of corticosteroids): ${ }^{20,27}$

- Mitoxantrone (57\%)

- Cyclophosphamide (19\%)

- Methotrexate (17\%)

- Azathioprine (15\%)

- Mycophenolate (9\%)

- Other $(13 \%)$
In Canada, mitoxantrone has not been used as commonly as it has been in Europe. Furthermore, when it has been used in Canada, it was often administered as a "mini induction" consisting of a short course of treatment. Although there are no data available at this time, it is possible that patients who receive a short course of mitoxantrone might not be at the same level of risk as those who were exposed for a longer time and/or received a larger cumulative dose. As previously stated, fingolimod should be considered as an immunosuppressant agent until its long-term safety profile has been more definitively established. Increased clinical vigilance is warranted in this patient segment, with clinical examination at least every six months. Clinicians may consider more frequent MRI (e.g., every 6-12 months, depending on hospital protocols). This is particularly relevant in light of a recent case report of pre-symptomatic PML diagnosis through frequent MRI monitoring in higher-risk patient groups, which led to a much earlier initiation of treatment with intravenous steroids and a better patient outcome..$^{28}$

\section{With Prior Immunosuppressant Treatment and >2 Years of Natalizumab Exposure}

Patients with all three quantified risk factors for PML (i.e., anti-JCV antibody-positive, with prior immunosuppressant use and more than two years of natalizumab treatment) are at the highest risk of developing PML. Notably, the risk of PML in seropositive patients beyond two years of treatment with natalizumab who have a prior history of immunosuppressant use is approximately 2.7 -fold higher (i.e., 10.6/1,000) than for those who have never received immunosuppressant therapy (i.e., $3.9 / 1,000) .^{20}$ Prior exposure to immunosuppressant therapy suggests this patient segment has more aggressive disease with many treatment failures and/or intolerance to conventional DMDs. For such patients, there are few remaining treatment options with evidence of efficacy. Patients in this segment may also have transitioned to a progressive form of disease, which may continue to progress despite continued natalizumab therapy. A serious discussion with patients in this risk category is needed to carefully assess the potential benefits and risks of continued natalizumab treatment, in the context of the risks and benefits of other potential therapeutic options. In patients with highly active MS who are responding well to natalizumab, the benefit may outweigh this increased risk, and patients may choose to continue treatment. Clinicians are reminded that the risk of PML does not appear to continue to increase beyond 36 months of treatment; however, there are relatively fewer patients with such long-term follow-up data, and estimates of PML incidence will most certainly change as more patients are followed for longer periods of time.

If natalizumab is continued, heightened clinical vigilance is recommended. Specifically, patients should be examined at least every six months with more frequent MRI (e.g., every 6-12 months).

\section{Conclusions}

Evidence to date suggests the two-step anti-JCV antibody assay is a useful clinical tool for risk stratification of patients on (or who are potential candidates for) natalizumab therapy. The recommendations for risk stratification by this expert panel are 
summarized in the Table. To date, there have been no cases of natalizumab-related PML in patients who were anti-JCV antibody-negative. The risk of PML is low for all patients during the first two years of treatment (i.e., $\leq 1.5 / 1,000),{ }^{20}$ even if they are anti-JCV antibody-positive and have a history of prior immunosuppressant use. Beyond two years of therapy, the risk of PML increases almost 3-fold, and is highest in those patients who have all three risk factors. Decisions to continue natalizumab beyond two years or to switch to another MS therapy will require careful evaluation and discussion of risks and benefits with individual patients, who may vary greatly in their degree of risk tolerance.

The availability of this two-step anti-JCV antibody assay represents a step forward in patient risk stratification. However, there are likely several as yet unknown risk factors that could further refine our ability to appropriately select candidates for MS treatments. Risk stratification will continue to evolve as new risk factors are identified and quantitated.

\section{ACKNOWLEDGMENT}

These consensus-based recommendations were prepared by Dr. Paul O'Connor with input and approval from a panel of Canadian MS neurologists specialized in the treatment of MS. This panel met together under the auspices of a clinical consultancy meeting sponsored by Biogen Idec Canada. The meeting sponsor provided information regarding the development and scientific validity of the two-step anti-JCV antibody assay but was in no way involved in drafting the risk stratification recommendations. Members of the expert panel included the following: Bar-Or A, Bhan V, Duquette P, Giuliani F, Kremenchutzky M, Lee L, Selchen D.

\section{DeClaration}

Dr. Paul O'Connor has received either personal compensation (for consulting, serving on a scientific advisory board, or speaking) or financial support for scholarly activities from pharmaceutical companies that develop products for MS, including Actelion, Biogen Idec, Celgene, Sanofi-Aventis, EMD Serono, Abbott Labs, Teva Pharmaceuticals, Bayer, Bio MS, Genentech, Lilly, Roche, and Novartis. He has received consultation fees from the MS Society of Canada. Grant support has been received from the MS Society of Canada, the National Institutes of Health and Direct MS.

\section{REFERENCES}

1. Biogen Idec Canada Inc. Tysabri (natalizumab) Product Monograph. November 1, 2010.

2. Polman $\mathrm{CH}$, O'Connor PW, Havrdova E, et al. A randomized placebo-controlled trial of natalizumab for relapsing multiple sclerosis. N Engl J Med. 2006;354:899-910.

3. Havrdova E, Galetta S, Hutchinson M, et al. Effect of natalizumab on clinical and radiological disease activity in multiple sclerosis: a retrospective analysis of the Natalizumab Safety and Efficacy in Relapsing-Remitting Multiple Sclerosis (AFFIRM) study. Lancet Neurol. 2009;8:254-60.

4. Balcer L, Galetta SL, Calabresi PA, et al. Natalizumab reduces visual loss in patients with relapsing multiple sclerosis. Neurology. 2007;68:1299-304.

5. Rudick RA, Miller D, Hass S, et al; AFFIRM and SENTINEL Investigators. Health-related quality of life in multiple sclerosis: effects of natalizumab. Ann Neurol. 2007;62:335-46.
6. Agostini HT, Ryschkewitsch CF, Singer EF, Stoner GL. Coinfection with two JC virus genotypes in brain, cerebrospinal fluid or urinary tract detected by direct cycle sequencing of PCR products. J Neurovirol. 1996;2:259-67.

7. Hellwig K, Gold R. Progressive multifocal leukoencephalopathy and natalizumab. J Neurol. 2011;258:1920-8.

8. Sunyaev SR, Lugovskoy A, Simon K, Gorelik L. Adaptive mutation in the JC virus protein capsid are associated with progressive multifocal leukoencephalopathy (PML). PLoS Genet. 2009;5: e1000368.

9. Tan CS, Koralnik IJ. Progressive multifocal leukoencephalopathy and other disorders caused by JC virus: clinical features and pathogenesis. Lancet Neurol. 2010;9:425-37.

10. Major EO. Progressive multifocal leukoencephalopathy in patients on immunomodulatory therapies. Annu Rev Med. 2010;61: $35-47$.

11. Langer-Gould A, Atlast SW, Green AJ, Bollen AW, Pelletier D. Progressive multifocal leukoencephalopathy in a patient treated with natalizumab. N Engl J Med. 2005;353:375-81.

12. Kleinschmidt-DeMasters BK, Tyler KL. Progressive multifocal leukoencephalopathy complicating treatment with natalizumab and interferon-beta-1a for multiple sclerosis. N Engl J Med. 2005;353:369-74.

13. Van Assche G, Van Ranst M, Sciot R, et al. Progressive multifocal leukoencephalopathy after natalizumab therapy for Crohn's disease. N Engl J Med. 2005;353:362-8.

14. Biogen Idec. Data on file as of February 29, 2012.

15. Foley J, Vermersch P, Gold R, et al. Natalizumab-associated progressive multifocal leukoencephalopathy outcomes. Int J MS Care. 2011;13(Suppl 3):7.

16. Clifford DB, De Luca A, Simpson DW, Arendt G, Giovannoni G, Nath A. Natalizumab-associated progressive multifocal leukoencephalopathy in patients with multiple sclerosis: lessons learned from 28 cases. Lancet Neurol. 2010;9:438-46.

17. Khatri BO, Man S, Giovannoni G, et al. Effect of plasma exchange in accelerating natalizumab clearance and restoring leukocyte function. Neurology. 2009;72:402-9.

18. Vermersch P, Kappos L, Gold R, et al. Clinical outcomes of natalizumab-associated progressive multifocal leukoencephalopathy. Neurology. 2001;76:1697-704.

19. Gorelik L, Lerner M, Bixler S, et al. Anti-JCV virus antibodies: implications for PML risk stratification. Ann Neurol. 2010;68: 295-303.

20. Sørensen PS, Bertolotto A, Edan G, et al. Risk stratification for progressive multifocal leukoencephalopathy in patients treated with natalizumab. Mult Scler. 2012;18:143-52.

21. Rudick RA, O'Connor PW, Polman CH, et al. Assessment of JC virus DNA in blood and urine from natalizumab-treated patients. Ann Neurol. 2010;68:304-10.

22. Bozic C, Richman S, Plavina T, et al. Anti-John Cunningham virus antibody prevalence in multiple sclerosis patients: baseline results of STRATIFY-1. Ann Neurol. 2011;70:742-50.

23. Moiola L, Sangalli F, Martinelli V, et al. Prevalence of anti-JCV antibodies in a cohort of natalizumab-treated multiople sclerosis patients from Italy. Neurology. 2011;76(Suppl 4):S30.007, S31.

24. Bloomgren G, Richman S, Hotermans C, et al. Contribution of natalizumab treatment duration, prior immunosuppressant use, and anti-JCV virus antibody status to the risk of progressive multifocal leukoencephalopathy in natalizumab-treated multiple sclerosis patients. Mult Scler J. 2011;17(Suppl 10):S451.

25. O'Connor PW. Use of natalizumab in multiple sclerosis patients. Can J Neurol Sci. 2010;37:98-104.

26. O'Connor PW, Goodman A, Kappos L, et al. Disease activity return during natalizumab treatment interruption in patients with multiple sclerosis. Neurology. 2011;76:1858-65.

27. Kappos L, Foley J, Gold R, et al. Overview of survival outcome and functional status in postmarketing cases of natalizumabassociated progressive multifocal leukoencephalopathy. Mult Scler J. 2011;17(10 Suppl):S131.

28. Phan-Ba R, Lommers E, Tshibanda L, et al. MRI preclinical detection and asymptomatic course of a progressive multifocal leucoencephalopathy (PML) under natalizumab therapy. J Neurol Neurosurg Psychiatry. 2012;83:224-6. 